\title{
New label advice for antibiotics
}

The label attached by pharmacists to antibiotic packaging has previously advised patients to continue taking the antibiotics until they are all finished. This advice has been in line with the approved product information. However, this advice may have contributed to the excessive use of antibiotics and antibiotic resistance. There is now awareness that the required duration of treatment may need a smaller quantity of antibiotic than the pack that is supplied to the patient., ${ }^{1,2}$

In consultation with other organisations, the Pharmaceutical Society of Australia has revised the cautionary advisory label used by pharmacists for antibiotics. It will now state, 'Take for the number of days advised by your prescriber.'

As a consequence of this change there are several important messages for prescribers and pharmacists:

- Prescribers should include the expected duration of therapy on the prescription and communicate the duration of therapy to the patient at the time of prescribing.

- Including a repeat for an antibiotic on the prescription by default is generally not appropriate.
- Pharmacists should confirm that the patient understands the prescribed duration of therapy. If the duration of therapy is not communicated on the prescription, and the patient does not know, the pharmacist should contact the prescriber to confirm the duration of therapy.

- Pharmacists should not dispense a repeat prescription for an antibiotic without first clarifying clinical appropriateness.

- Prescribers and pharmacists should make patients aware that the advice to take the antibiotics for the prescribed duration of therapy may be inconsistent with the advice that is currently in Consumer Medicine Information for the antibiotic.

- Patients should be advised to take any 'leftover' antibiotics back to the pharmacy for disposal.

The new label is expected to be used from January 2021.
Aust Prescr 2020;43:211

https://doi.org/10.18773/ austprescr.2020.072

\section{REFERENCES}

1. McGuire TM. Does size matter? Addressing pack size and antibiotic duration. Aust Prescr 2019;42:2-3. https://doi.org/ 10.18773/austprescr.2019.005
2. Wilson $\mathrm{HL}$, Daveson K, Del Mar CB. Optimal antimicrobial duration for common bacterial infections. Aust Prescr 2019;42:5-9. https://doi.org/10.18773/austprescr.2019.00 